Marquette University

e-Publications@Marquette

School of Dentistry Faculty Research and

Publications

Dentistry, School of

5-1-2007

\title{
Traumatic Neuroma Following Sagittal Split Osteotomy of the Mandible
}

\author{
R. H. Kallal \\ Northwestern University \\ F. G. Ritto \\ Pedro Ernesto University Hospital \\ Luis Eduardo Almeida \\ Marquette University, luis.almeida@marquette.edu \\ D.J. Crofton \\ University of Florida \\ G. P. Thomas
}

Accepted version. International Journal of Oral and Maxillofacial Surgery, Vol. 36, No. 5 (May 2007): 453-454. DOI. (C) 2007 Published by Elsevier Ltd. Used with permission.

Luis Eduardo Almeida was affiliated with Division of Oral and Maxillofacial Surgery, Pedro Ernesto University Hospital, Rio de Janeiro, RJ, Brazil at the time of publication. 


\title{
Marquette University
}

\section{e-Publications@Marquette}

\section{Dentistry Faculty Research and Publications/School of Dentistry}

This paper is NOT THE PUBLISHED VERSION; but the author's final, peer-reviewed manuscript. The published version may be accessed by following the link in the citation below.

International Journal of Oral and Maxillofacial Surgery, Vol. 36, No. 5 (May 2007): 453-454. DOI. This article is (C) Elsevier and permission has been granted for this version to appear in ePublications@Marquette. Elsevier does not grant permission for this article to be further copied/distributed or hosted elsewhere without the express permission from Elsevier.

\section{Traumatic neuroma following sagittal split osteotomy of the mandible}

\author{
R. H. Kallal
} Division of Dental and Oral and Maxillofacial Surgery, The Feinberg School of Medicine, Northwestern University, Chicago, IL, USA

F. G. Ritto Division of Oral and Maxillofacial Surgery, Pedro Ernesto University Hospital, Rio de Janeiro, RJ, Brazil

\section{E. Almeida}

School of Dentistry, Marquette University, Milwaukee WI

Hospital Evangelico de Curitiba, Curitiba, PR, Brazil

D. J. Crofton

College of Dentistry Extramural Programs, University of Florida, Gainesville, FL, USA

G. P. Thomas

San Mateo, CA, USA

\section{Abstract}

A 16-year-old male underwent bilateral sagittal split osteotomy of the mandible to correct a mandibular deficiency. Twenty-one years later, a routine panoramic radiograph revealed a radiolucent lesion on the left side 
of the mandible. The lesion was biopsied. As the patient did not have symptoms and the lesion was connected to the inferior alveolar nerve, the lesion was not totally excised in order to preserve nerve function. The histological features were consistent with traumatic neuroma, and no further surgical procedure was planned.

\section{Introduction}

A traumatic neuroma, which is an overgrowth of nerve fibres following severance or damage to a nerve, represents an attempt at repair rather than a true neoplasm $\underline{5}, \underline{7}$. It can be classified as a true neuroma $-a$ tumour composed mainly of nerve tissue - or a false neuroma - a tumour composed of mainly connective tissue derived from the nerve sheath $\underline{8}$. The nerve elements can be injured by different factors, including pressure, ischaemia, crushing, cuts, lacerations, stretching or bleeding into the surrounding area $\underline{8}$. Common signs and

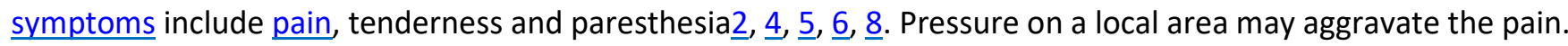
Infiltration of local anaesthesia into the painful region provides relief $\underline{2}, \underline{5}, \underline{6}$.

The technique of sagittal split osteotomy of the mandible, first published by Obwegeser in 1955, is one of the most common procedures used to correct mandibular developmental anomalies. Complications may occur; for example, skeletal and dental relapse, haemorrhage, disturbance of inferior alveolar nerve function and fragmentation of the ramus with necrosis and sequestrae formation $\underline{1}, \underline{2}, \underline{3}, \underline{6}, \underline{7}$. Here is reported a case of an asymptomatic traumatic neuroma that developed following bilateral sagittal split osteotomy to correct a mandibular deficiency.

\section{Report of case}

A 16-year-old male underwent bilateral sagittal split osteotomy of the mandible with an advancement of $8 \mathrm{~mm}$. During surgery the inferior alveolar nerve was identified in the distal segment. The third molar was removed during surgery on the left side, but the right side was left in situ because it was still covered by bone. Bleeding from a branch of the facial artery occurred on the left side, and was controlled with pressure and Surgicel. The bone segments were stabilized with bilateral wires. In the postoperative period the patient complained of $\underline{\text { numbness }}$ on the left side in both the lip and chin, but feeling had returned by approximately 6 months after surgery. The postoperative oedema was more pronounced on the left side, and lasted for 3 months.

Even though the patient remained asymptomatic, a radiolucent lesion was observed in the left mandibular ramus, on a routine panoramic radiograph, taken 21 years after the orthognathic surgery (Fig. 1). An incisional biopsy was planned so that a histological analysis of the lesion could be performed. A submandibular approach was used to access the lesion, which had a dumbbell shape and was intimately connected to the inferior alveolar nerve. As the patient did not have symptoms, it was decided not to remove the mass in toto, but only to remove two sections for microscopic examination, in order that nerve function would be retained. A membrane was placed around the nerve. The histological features of the mass were consistent with a diagnosis of traumatic neuroma (Fig. 2). Three years after the biopsy, the lesion had not grown any larger, and the patient retained only a small area of paraesthesia between the lip and chin on the left side.

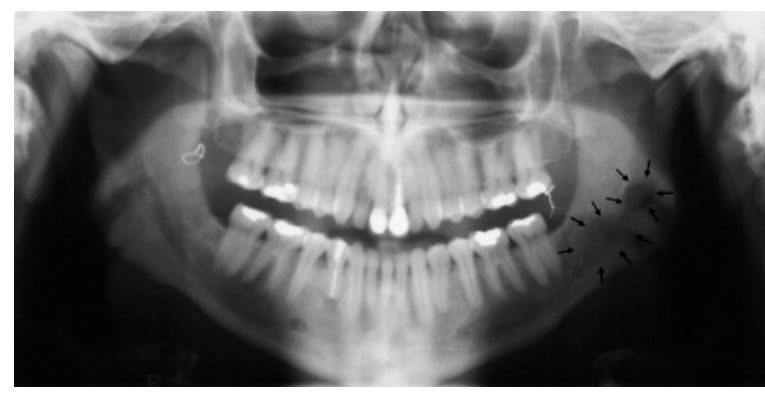

Fig. 1. Radiolucent lesion on the left ramus (arrows). 


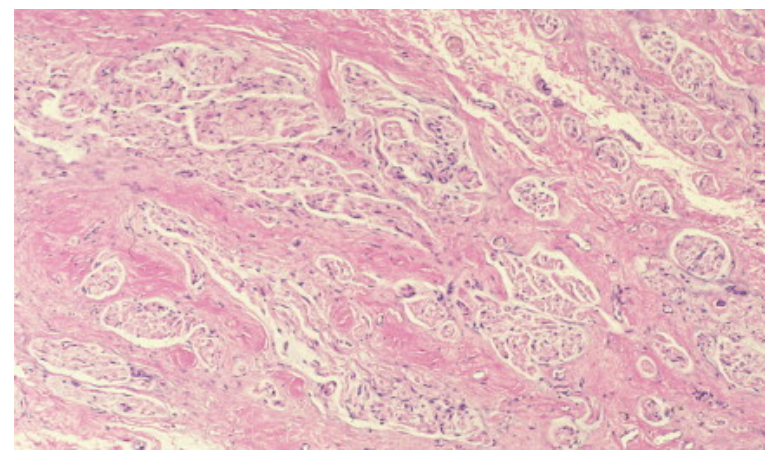

Fig. 2. Microscopic analysis of lesion (haematoxylin \& eosin, $\times 100)$.

\section{Discussion}

Although disturbance of sensation involving the inferior alveolar nerve is commonly reported after bilateral sagittal split osteotomy of the mandible, there are only four reported cases in the English language literature of traumatic neuroma formation following such surgery. Two of the cases were symptomatic $\underline{2}, \underline{7}$ and the other two asymptomatic $\underline{1}, \underline{6}$. In all four of the previous cases, the mass was totally excised. Chau et al. $\underline{2}$ have suggested that surgical removal of the neuroma is worth a single attempt if the neuroma can be located and if infiltration of a local anaesthetic provides relief. Nerve section and alcohol blocks appear to be ineffective, or even harmful $\underline{2}, \underline{6}$.

In the case presented, the traumatic neuroma was asymptomatic and it was therefore decided not to excise the mass. Instead, the superficial tissue was excised from the mass for histopathologic examination, but the nerve itself was left intact. Since the lesion had likely been present for over 23 years, there seemed little likelihood of increased growth and no concern about permanent damage by leaving it.

\section{References}

\section{S. Appiah-Anane Amputation-neuroma: a late complication following sagittal split osteotomy of the} mandible J Oral Maxillofac Surg, 49 (1991), pp. 1218-1220

2 M.N.Y. Chau, E. Josen, K.M. Lee Traumatic neuroma following sagittal mandibular osteotomy Int J Oral Maxillofac Surg, 18 (1989), p. 95

$\underline{3}$ L. Fiamminghi, C. Aversa Lesions of the inferior alveolar nerve in sagittal osteotomy of the ramus: experimental study J Maxillofac Surg, 7 (1979), pp. 125-128

4 S.S. Hecht Amputation neuroma Oral Surg Oral Med Oral Pathol, 10 (1957), pp. 475-479

5 O.C. Rasmussen Painful traumatic neuromas in the oral cavity Oral Surg Oral Med Oral Pathol, 49 (1980), pp. 191-195

$\underline{6}$ N.B. Sayan, C. Üçok Asymptomatic traumatic neuroma after mandibular sagittal split osteotomy: a case report J Oral Maxillofac Surg, 60 (2002), pp. 111-112

7 S.M. Sheridan Traumatic neuroma following sagittal split mandibular osteotomy Br J Oral Surg, 21 (1983), pp. 198-200

$\underline{8}$ H.H. Swanson Traumatic neuromas: a review of literature Oral Surg Oral Med Oral Pathol, 14 (1961), pp. 317326 